\title{
MEIO AMBIENTE COMO TEMA TRANSVERSAL NO CONTEXTO DE UM CURSO EXPERIMENTAL DE CURTA DURAÇÃO E DA METODOLOGIA DA PROBLEMATIZAÇÃO
}

Cátia Silene Carrazoni Lopes Viçosa ${ }^{1}$

Aline da Silva Goulart ${ }^{2}$

Débora Lopes Viçosa ${ }^{3}$

Andréia Caroline Fernandes Salgueiro ${ }^{4}$

Vanderlei Folmer ${ }^{5}$

Resumo: Apresentamos a utilização do tema transversal Meio Ambiente, trabalhado por meio da Metodologia da Problematização, com o objetivo de auxiliar os estudantes no processo de construção de percepções sobre o que é Ciência. A proposta foi desenvolvida em um curso experimental de $20 \mathrm{~h}$, com educandos dos anos finais do Ensino Fundamental de uma escola com baixo índice de desenvolvimento escolar. Os resultados indicaram o envolvimento ativo dos estudantes a partir da formulação dos problemas, levantamento das hipóteses e desenvolvimento dos experimentos na busca por soluções. A partir da metodologia adotada se observou mudanças nas percepções sobre Ciência e sobre os temas emergidos, auxiliando na construção de novos saberes.

Palavras-chave: Ciência; Transversalidade; Experimentação, Modelo Didático.

\footnotetext{
1 Doutoranda PPG Educação em Ciências: Química da Vida e Saúde, Universidade Federal do Pampa. Email: catialopes00@hotmail.com. Link para o Lattes: http://lattes.cnpq.br/2756461468265473

2 Mestranda PPG Bioquímica, Universidade Federal do Pampa. E-mail: alinefsgoulart@gmail.com. Link para o Lattes: http://lattes.cnpq.br/3116711385113926

${ }^{3}$ Mestranda PPG Educação em Ciências: Química da Vida e Saúde Universidade Federal do Pampa. Email: fisiodlv@gmail.com. Link para o Lattes: http://lattes.cnpq.br/7846180835442763

4 Doutora em Bioquímica, Universidade Federal do Pampa. E-mail: acfsalgueiro@gmail.com. Link para o Lattes: http://lattes.cnpq.br/5529127283220286

${ }^{5}$ Doutor em Ciências Biológicas, Universidade Federal do Pampa. E-mail: vanderleifolmer@unipampa.edu.br. Link para o Lattes: http://lattes.cnpq.br/8135232309980269
} 
Abstract: We present the use of the transversal theme Environment, explored through the Problematization Methodology, to encourage students to build perceptions about what Science is. The proposal was developed in an experimental course of 20 hours, with students from the final years of an elementary school with low index of school development. The results indicated the active involvement of students from the problems formulation, hypotheses survey, and experiments development in the search for solutions. From the adopted methodology, in which the subject is the builder of his own knowledge, it was possible to observe changes in the perceptions about Science and the emerged themes, helping in the construction of new knowledge.

Keywords: Science; Transversality; Experimentation, Didactic Model.

\section{Introdução}

Trabalhar Ciência na atualidade tem se mostrado como um desafio para escola, emergindo questões relacionadas à "Como ensinar?" e "Como auxiliar nas construções coletivas de conhecimento?". Para Viçosa et al. (2016) é preciso repensar os objetivos das condutas educacionais, mediante concepções que integrem educandos e educadores na construção de conhecimentos, a partir de temáticas atuais. Nesse contexto, práticas pedagógicas contextualizadas com temas pertinentes aos educandos auxiliariam no processo de aprendizagem.

Para incorporar a realidade do educando ao espaço escolar, consta na Base Nacional Comum Curricular (BNCC), que temas contemporâneos e condizentes a realidade dos educandos deve ser abordada de forma transversal e integrada às propostas pedagógicas (BRASIL, 2017). Assim, entre distintas estratégias didático-pedagógicas que possam melhorar o ensino de Ciências, se destaca a Metodologia da Problematização (MP). Para Berbel (2016), essa metodologia instiga os educandos a buscarem ativamente soluções para as hipóteses criadas, desde que representem problemas reais a serem resolvidos.

Uma possibilidade para se trabalhar a MP são atividades práticas em laboratório. Para Lima e Garcia (2011), em atividades de laboratório o educando pode vivenciar fatos e métodos científicos. Essas vivências auxiliam na desmistificação de conceitos errôneos acerca do que é Ciência, a partir do momento em que experimentam e problematizam a ação. A prática laboratorial deve ainda contribuir na construção de saberes por meio da problematização do conhecimento científico para questões reais do educando, permitindo uma nova concepção do que é Ciência (LIMA; GARCIA, 2011).

Assim, a Ciência pode ser trabalhada a partir de propostas transversais 
auxilia o sujeito a atuar em uma sociedade complexa e em permanente transformação. Deste modo, com as mudanças aceleradas da sociedade, entende-se ser imprescindível inserir nas práticas educativas temas contemporâneos e significativos como eixo unificador na construção de conhecimentos.

Desta forma, cita-se o Meio Ambiente como tema urgente a ser trabalhado na escola. Colombo (2014) defende o envolvimento ativo dos estudantes com essa temática, relacionando-a às ações do homem com o ambiente, por meio da problematização. Assim, este tema emerge como uma possibilidade para instigar a reflexão e a construção de novas condutas dos sujeitos frente aos cuidados com o ambiente em que estão inseridos.

Para que isto se efetive, Magalhães Junior e Tomanik (2013) entendem a necessidade de uma formação que vincule os conteúdos com o cotidiano e realidade dos alunos. Isso é possível a partir de uma formação que trabalhe a problematização, ampliando os conhecimentos e apresentando novas informações e metodologias eficazes para a prática docente. Assim, a problematização, aliada a distintos temas, auxilia na busca por soluções e estratégias que tendam a solucionar os problemas observados pelos estudantes (WOLLMANN et al., 2014).

Nesse contexto, abordagens transversais devem implicar em metodologias que envolvam questões pertinentes aos educandos, resultando em uma aprendizagem significativa (MAGALHÃES JUNIOR; TOMANIK, 2013). Desta forma, espera-se que os enfoques transversais possam contribuir na articulação entre o saber científico e o saber cotidiano. Com base no exposto, objetivamos aqui apresentar as contribuições da utilização do tema transversal Meio Ambiente como objeto de problematização no processo de construção de saberes dos educandos a partir de um curso experimental de curta duração.

\section{Metodologia}

Os Cursos Experimentais de Curta Duração, ofertados pelo nosso grupo, são norteados a partir da proposta da Rede Nacional de Educação e Ciência (RNEC) e suas atividades são desenvolvidas preferencialmente em escolas com baixo Índice de Desenvolvimento da Educação Básica (IDEB). 0 grupo é formado por um professor coordenador, dois professores colaboradores e por monitores de diferentes áreas do conhecimento: graduandos de Ciências da Natureza, Enfermagem, Fisioterapia, e pósgraduandos de Educação em Ciências: Química da Vida e Saúde e de Bioquímica, formando assim uma equipe multidisciplinar.

A RNEC foi idealizada pelo Prof. Leopoldo de Meis e criada em 1985 na Universidade Federal do Rio de Janeiro, juntamente com outros grupos de distintas instituições de ensino superior. A RNEC partiu da concepção de que muitos educandos são excluídos do mundo da cultura e da Ciência por falta de oportunidades e de acesso à informação. Assim, a RNEC tem por objetivo 
integrar o educando do Ensino Básico à universidade e promover o conhecimento científico por meio de ações transversais e da MP.

As atividades aqui descritas foram desenvolvidas com 25 estudantes dos anos finais do Ensino Fundamental de uma escola pública municipal localizada em uma região periférica da cidade de Uruguaiana/RS. No IDEB de 2015, a escola apresentou índice de 3,5, considerado abaixo da meta projetada que seria de 4,5 (BRASIL, 2019). O curso com duração de uma semana (20h) foi realizado em turno inverso ao das aulas e desenvolvido em dois espaços: na escola participante no primeiro e último dia, e nos laboratórios da universidade no segundo, terceiro e quarto dias da semana.

A proposta se baseia na MP utilizando os três momentos pedagógicos, que segundo Muenchen e Delizoicov (2014) são caracterizados pela Problematização Inicial, Organização do Conhecimento e Sistematização do Conhecimento. Para os autores, a primeira etapa visa a exposição dos conhecimentos prévios sobre o tema; a segunda objetiva estudar e pesquisar sobre os conhecimentos problematizados, e a terceira etapa finaliza com análise e interpretação das situações iniciais que determinaram o estudo. Ao final, ocorre ainda a socialização dos resultados encontrados e dos saberes produzidos de maneira lúdica (teatro, paródias, cartazes etc.).

Detalhadamente, as atividades foram desenvolvidas da seguinte forma:

i) Na etapa inicial, realizada na escola em turno inverso ao das aulas, ocorreu, em formato de roda de conversa, a apresentação de monitores e participantes. Na sequência, os 25 participantes foram divididos em três grupos por meio de dinâmica: os participantes tiveram que retirar de uma caixinha um cartão, dentro da caixa havia cartões em três diferentes cores. Os grupos foram formados a partir da semelhança da cor escolhida. Este tipo de dinâmica permitiu que os grupos tivessem diferentes perfis de educandos. Cada grupo ficou sob responsabilidade de um monitor (graduando ou pós-graduando) que distribuiu entre os participantes diários de laboratório para as anotações.

Na sequência, os estudantes respondem à questão "O que é Ciência?". Após, foram apresentados ao tema norteador do curso (Meio Ambiente) e foram incentivados a verbalizar seus conhecimentos acerca do assunto através da técnica Brainstorming. De acordo com Marques et al. (2017), o Brainstorming caracteriza-se como uma técnica de caráter exploratório que busca primordialmente incentivar o surgimento de ideias e propostas acerca de determinado tema. A seguir, os grupos formados por estudantes foram incentivados a formular problemas a partir das questões emergidas no Brainstorming, e com o auxílio dos monitores, elaboram hipóteses.

Para finalizar as atividades desse dia, foi disponibilizado aos grupos frascos que continham moscas-da-fruta (Drosophila melanogaster Meigen, 1830). Esses continham o meio de alimentação das moscas (farinha de milho, fermento biológico, ágar, açúcar e água) e moscas em diferentes fases de ciclo de vida. Na intenção de instigar o pensar dos participantes, não foi informado o 
que estava presente nos frascos para que eles formulassem suas hipóteses e expusessem ao grande grupo. Após chegarem em um consenso sobre o conteúdo dos frascos, os monitores apresentaram a eles a $D$. melanogaster que é utilizada como modelo experimental em distintos laboratórios de pesquisas.

Em todos os experimentos se utilizou como modelo experimental a $D$. melanogaster. Conforme Rocha et al. (2013), este modelo é utilizado com sucesso em diferentes áreas da Ciência por ser de fácil manuseio, apresentar ciclo de vida curto, alta taxa de reprodução e baixo custo econômico de manutenção em laboratório. Sua utilização é válida por possuir estrutura física facilmente observável em lupa, genoma sequenciado e menor quando comparado ao de outros eucariontes (ROCHA et al., 2013). Essas características as tornam aliadas dos professores no momento de transformar aulas teóricas de Ciências em práticas interessantes e envolventes.

ii) $\mathrm{Na}$ etapa intermediária, desenvolvida na universidade, os participantes foram apresentados ao laboratório de Ciências: equipamentos, vidrarias. Os participantes também foram informados sobre as medidas de biossegurança necessárias às práticas de laboratório. Os estudantes receberam jalecos e luvas, e tinham à disposição máscaras e óculos de segurança.

A partir do problema inicial elaborado, cada grupo relatou o tipo de material que iriam utilizar para testar suas hipóteses e a maneira que pretendiam desenvolver os experimentos. Os estudantes foram incentivados a registrar todos os procedimentos científicos no diário de laboratório previamente disponibilizado. Os procedimentos utilizaram distintos materiais de laboratório (pipeta, Becker, Erlenmeyer, termômetro, Bico de Bunsen, Tela de Amianto etc.). Os demais materiais relacionados à temática problematizadora, que não haviam no laboratório, foram listados e comprados pela coordenação do curso e disponibilizados no segundo dia.

Entre os materiais que não haviam no laboratório, cita-se a solicitação para o experimento do Efeito Estufa: papel alumínio, filme plástico, copo descartável de $200 \mathrm{ml}$ e filme plástico. Para o experimento das Plantas Medicinais os participantes solicitaram a Metformina®, medicação utilizada para tratar Diabetes mellitus, e se prontificaram a levar amostras de exemplares medicinais que possuíam em casa como Boldo, Macela, Hortelã, Carqueja, Capim Cidró e Pata de Vaca. Porém, para garantir o sucesso da atividade, os monitores também levaram amostras de plantas. No experimento de Poluição Ambiental o material solicitado pelos educandos foi arroz, liquidificador, algodão, fósforo, cigarro e óleo diesel.

Em todas as etapas os participantes foram estimulados a seguir, entre distintos métodos científicos, o método adotado pelo grupo promotor do curso para pesquisas experimentais, anotando diariamente os procedimentos, a validação ou não das hipóteses elaboradas, os resultados diários da pesquisa e a avaliação das estratégias adotadas. Nesta fase, os grupos tinham 
autonomia para repetir os experimentos quando os resultados obtidos não condiziam com as hipóteses formuladas, problematizando as questões emergidas. A repetição objetivou verificar se a hipótese elaborada por eles estava incorreta ou se havia erro na realização do procedimento.

Ao final de cada dia de experimento os estudantes foram convidados a socializar entre seus pares as atividades e conclusões parciais do grupo. No penúltimo dia do curso, os grupos foram orientados a planejar a sistematização e socialização dos resultados experimentais de forma lúdica para os demais colegas.

iii) No último dia os grupos socializaram o problema de pesquisa elencado inicialmente, os procedimentos e materiais empregados, e os resultados e conclusões dos experimentos. Essa apresentação ocorreu de maneira lúdica, por meio de cartazes, paródias e teatro. Ao final, os estudantes respondem novamente à questão "O que é Ciência?". Os monitores esclareceram algumas dúvidas e instigaram os participantes a manifestarem sua percepção sobre o curso que encerrou com confraternização entre estudantes e monitores.

\section{Resultados}

Objetivamos apresentar aqui uma proposta de trabalho com o tema transversal Meio Ambiente, associado a um Curso Experimental de Curta Duração, a partir da MP. Com essa metodologia, busca-se conduzir o estudante a tomar consciência de seu mundo e agir intencionalmente para transformá-lo, com vistas a uma sociedade melhor (BERBEL, 2016). Esse método configura-se como potente ferramenta a ser utilizada no ensino de Ciências, no intuito de garantir aulas que contemplem a construção do conhecimento. Neste contexto, os resultados abaixo apresentados visam contribuir na aplicação de atividades que utilizem o tema Meio Ambiente como objeto de problematização, e que tenham por objetivo um ensino embasado na investigação.

Nesse sentido, após a apresentação do tema transversal Meio Ambiente e do Brainstorming, surgiram as seguintes temáticas geradoras: Efeito Estufa, Plantas Medicinais e Poluição Ambiental. Para Freire (2014, p.87) o trabalho de investigação com tema gerador "implica, necessariamente, uma metodologia que não pode contradizer a dialogicidade da educação libertadora". Ainda, segundo Freire (2014) deve contribuir na conscientização dos indivíduos em torno de si mesmos.

No tema Efeito Estufa, os educandos utilizaram a Biofísica e Bioquímica para simular o efeito estufa e relacionar as consequências ao Meio Ambiente. Na proposta de Plantas Medicinais, foi trabalhada sua utilização responsável e a preservação ambiental. Na temática Poluição Ambiental, o foco foram as implicações da poluição à saúde humana. 


\section{a) Efeito Estufa}

A Biofísica tem por princípio o estudo dos conceitos da física aplicados aos sistemas biológicos, e a Bioquímica trata dos processos químicos que ocorrem nos organismos vivos. Segundo Cauduro e Lüdke (2017), estas áreas interdisciplinares utilizam os princípios e leis da Física e de Química para entender, descrever e avaliar o funcionamento dos sistemas biológicos. Desta forma, os educandos tendo como objeto de problematização o Efeito Estufa, fizeram uso da Biofísica e Bioquímica para simular este fenômeno na atmosfera e suas consequências para o ser humano (Figura 1).

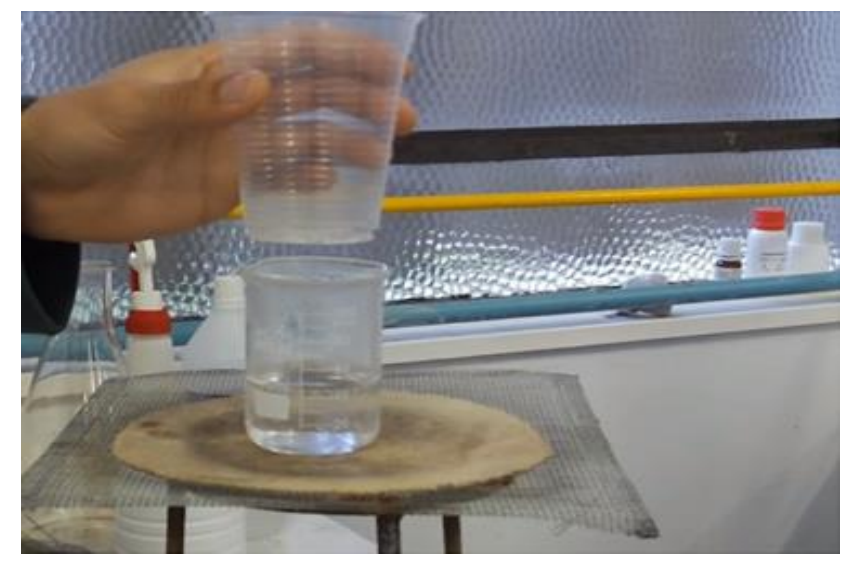

Figura 1: Experimento Efeito Estufa.

Fonte: Elaborado pelos autores (2019)

Nesta proposta, os participantes realizaram experimentos que simularam o efeito estufa utilizando entre os materiais copos descartáveis, água, filme plástico, tripé de ferro, tela de amianto, bico de Bunsen, termômetro, Becker e tela fina. Para chegar ao resultado esperado, os educandos utilizaram como gerador do efeito o vapor de água $(\mathrm{H} 2 \mathrm{O})$ por entenderem que este é encontrado em suspensão na atmosfera e por não ser nocivo para a realização do experimento. Empregaram ainda o uso do modelo experimental $D$. melanogaster para simular como podem ser as consequências do Efeito Estufa sobre os seres vivos e no Meio Ambiente.

No experimento, os educandos adicionaram $50 \mathrm{ml}$ de água em um Becker. A vidraria foi aquecida em cima da tela de amianto utilizando o Bico de Bunsen até a água atingir $100^{\circ} \mathrm{C}$. Paralelo a este procedimento, foram retiradas dos frascos quarenta $D$. melanogaster, seguindo as orientações dos monitores, e colocadas em número igual em dois copos descartáveis: um lacrado com filme plástico e outro fechado com tela fina, permitindo a passagem de ar. Ao chegar na temperatura pretendida, o Bico de Bunsen foi desligado e o copo lacrado foi colocado em cima do Becker por dois minutos. Os participantes perceberam que a maioria das moscas ficaram atordoadas, com dificuldades para voar, ficando alojadas no fundo do copo. No segundo copo foi repetido o 
mesmo procedimento, porém os educandos identificaram que menos de $10 \%$ das $D$. melanogaster demonstraram dificuldade em se locomover.

No decorrer do experimento, os educandos foram problematizando quais são os principais gases responsáveis por intensificar esse fenômeno natural e torná-lo nocivo ao meio ambiente em geral. Para Viçosa et al. (2017), a problematização é uma proposta de ensino que parte da realidade dos sujeitos; possibilita identificar o que precisa ser mudado e buscar os conhecimentos necessários para essas transformações. Essas características são essenciais para atribuir maior sentido ao que está sendo estudado, potencializando a aprendizagem.

Os educandos concluíram, a partir da problematização, que o experimento simulou corretamente como ocorre o efeito estufa. Essa conclusão baseou-se no fato de que, apesar dos dois copos serem expostos ao calor, o copo lacrado aumentou a temperatura em seu interior e no copo coberto com tela, com passagem de ar permitida, os efeitos não foram tão consideráveis quanto no copo lacrado. Ainda, na problematização final, emergiu o quanto a ação do homem contribui para o aumento deste fenômeno e que tipos de ações podem amenizar a emissão de gases no meio em que estão inseridos.

b) Plantas Medicinais

A escolha das Plantas Medicinais como tema gerador de problematização se deve a sua utilização como recurso medicinal por parte da população, por ser de fácil acesso e baixo custo. Para Pereira et al. (2019), essa temática potencializa a promoção e o desenvolvimento da Educação Ambiental e proporciona um maior conhecimento sobre as plantas, suas funções e importância na sociedade e na natureza. Assim, seguindo a metodologia proposta pelo curso, foi realizada uma problematização inicial sobre plantas medicinais.

Entre as plantas medicinais mais conhecidas, os participantes citaram a Carqueja (Baccharis genistelloides), Boldo (Peumus boldus), Macela (Achyrocline satureioides), Hortelã (Mentha), Capim cidró (Cymbopogon citratus) e Pata de Vaca (Bauhinia forficata) (Figura 2). A partir deste conhecimento prévio, foi solicitado que, se possível, eles trouxessem no dia seguinte uma amostra de cada uma das plantas citadas para utilizarmos como material de experimentação. 


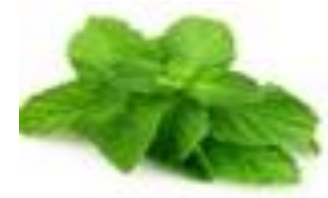

Hortela

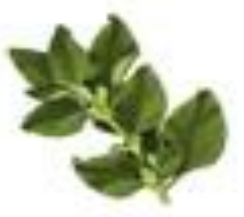

Boldo

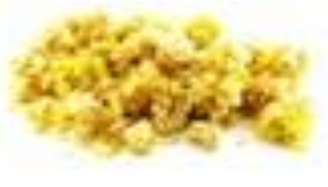

Macela

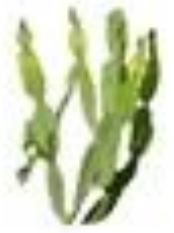

Carqueja

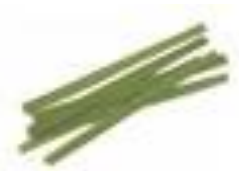

Capim Cidró

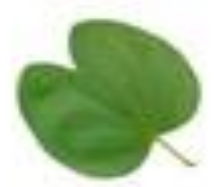

Pata de Vaca

Figura 2: Objetos de problematização.

Fonte: Elaborado pelos autores (2019)

$\mathrm{Na}$ sequência, os participantes elaboram problemas utilizando os exemplares das plantas medicinais supracitadas. Entre os principais questionamentos emergidos cita-se:

- A superdosagem pode ter consequências?

- Podemos misturar chá com medicação?

- A mistura delas causa alguma reação?

Para instigar a busca por soluções, os monitores questionaram de que forma eles poderiam responder a estas perguntas. Os educandos acordaram que eles não poderiam testar, pois não sabiam o quanto as plantas podiam ou não causar consequências.

A partir do uso do modelo, os educandos concluíram que se preparadas de forma incorreta, as plantas medicinais podem representar um perigo para a saúde. Eles chegaram a essa conclusão na observação final, pois no vidro que continha alta concentração de extrato das plantas as $D$. melanogaster morreram, e sobreviveram no que continha uma dose equilibrada dos extratos. Concluíram ainda, que a associação de medicação para Diabetes (Metformina $\AA^{\circledR}$ ) com a planta pata de vaca, pode ser prejudicial à saúde, pois no experimento que continha somente chá ou somente medicação os modelos sobreviveram, e no que associou chá com a medicação algumas das $D$. melanogaster morreram.

Os participantes inferiram ainda sobre a importância de preservar as plantas medicinais, sendo que elas auxiliam em pesquisas pela busca de novos medicamentos para diversas doenças. 
c) Poluição Ambiental

A poluição ambiental é caracterizada pela introdução de substâncias ou energia de forma acidental ou intencional no meio ambiente, com consequências negativas para os seres vivos. Conforme Segatto (2013), um dos grandes problemas para a sociedade é saber o que fazer com a grande quantidade de lixo e gases que são produzidos diariamente. Desta maneira, considerando a relevância do tema, e após discussão e problematização com os educandos, definiu-se que o tema gerador de problematização do curso seria a Poluição Ambiental.

Para desenvolvimento da proposta, foi sugerido pelos monitores o uso das $D$. melanogaster como modelo experimental. $O$ emprego deste modelo possibilitou aos educandos, após a problematização inicial, a elaboração de distintos experimentos relacionando a poluição ambiental com a saúde dos seres vivos. Permitiu ainda, a organização dos procedimentos que iriam comprovar ou não as hipóteses levantadas. Cita-se, entre os problemas emergidos:

- O pó de arroz, produzido pelo beneficiamento do grão em engenhos situados na área urbana da cidade, afeta a saúde da população?

- A fumaça do cigarro é prejudicial à saúde?

- Os gases emitidos pela queima de combustível de motores dos carros afetam a saúde?

Nesta perspectiva, com os experimentos, foi verificado se o pó de arroz, produzido por eles por meio da trituração do grão, e inserido no Becker (fechado com tecido fino para passar o ar) em que estavam as $D$. melanogaster é ou não prejudicial ao processo respiratório. No experimento do cigarro, ele foi adaptado aceso na tampa de um pote de vidro para produção de fumaça e observação do comportamento do modelo experimental com a situação criada. $\mathrm{Na}$ produção de gases oriundos da queima de combustíveis fósseis, foi queimado um pequeno chumaço de algodão umedecido com diesel para produção de fumaça, e inserido no vidro (tampado com tecido para permitir a passagem de ar) em que estavam as $D$. melanogaster, retratado na Figura 3.

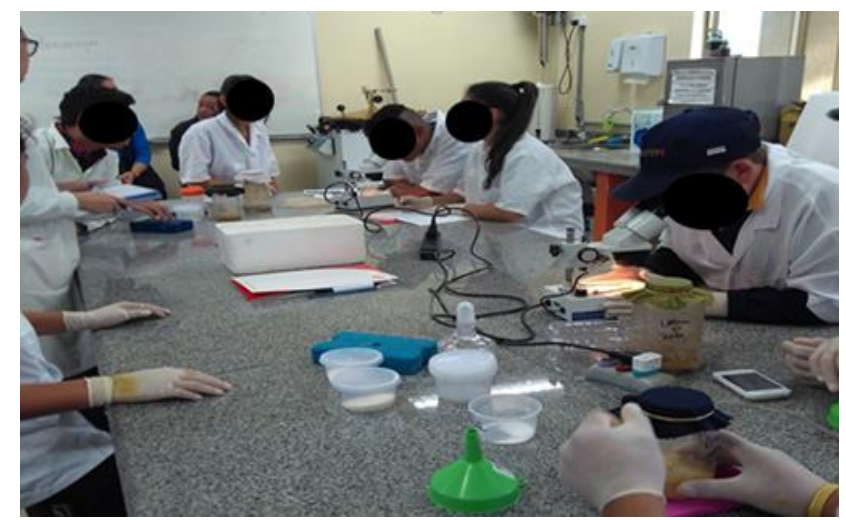

Figura 3: Experimento Poluição ambiental. Fonte: Registro realizado pelos autores (2019). 
Os resultados obtidos pelos educandos indicaram que o pó de arroz, a fumaça do cigarro e a produção de gases pela queima de combustível são prejudiciais à saúde. Essa conclusão foi originada após a finalização dos experimentos, pois a maioria das $D$. melanogaster morreram ou ficaram desorientadas pelo pó, fumaça e gases produzidos. Desta forma, para Gomes (2015), o emprego da $D$. melanogaster como modelo didático auxilia a interligar conteúdo teórico a questões pertinentes ao cotidiano dos educandos, provocando um entendimento mais amplo sobre o tema.

A partir deste dado, os educandos realizaram discussões referentes a importância da Ciência na constatação de fatores que geram poluição ambiental e consequentemente afetam o meio em que estão inseridos. Colombo (2014) destaca ser eficaz discutir as problemáticas ambientais por diferentes aspectos, ampliando a visão, percepção e reflexão do aluno sobre como contribuir para melhoria do meio ambiente. Assim, através da proposta, os participantes foram muito além de discutir sobre o Meio Ambiente, sendo capazes de refletir sobre o impacto da Ciência sobre distintas questões ambientais.

\section{Discussão}

As tendências do século XXI indicam que a característica central da educação é o deslocamento do enfoque individual para o enfoque social, político e ideológico (GADOTTI, 2000). O processo de ensino deve conceber uma relação diferenciada com o educando, onde se observa uma trajetória de construção do saber e promoção da aprendizagem. Deste modo, os procedimentos de ensino são tão importantes quanto os próprios conteúdos de aprendizagem.

Assim, conforme Freire (2014), emergem os temas geradores, que aliados a problematização, permitem aos educandos a transposição da visão ingênua para uma visão crítica e reflexiva de sua realidade, implicando na contextualização e em uma postura decisória frente ao mundo. A contextualização permite aos educandos processar informações que os aproximam da sua própria realidade, promovendo significado para os conhecimentos construídos. Conforme Oliveira et al. (2017) é necessário superar as práticas de ensino engessadas e pautadas na memorização de conceitos científicos, que não fazem parte do cotidiano dos estudantes.

De fato, é preciso identificar as deficiências presentes na técnica de ensino tradicional e propor novas metodologias de ensino-aprendizagem que visem sanar essas lacunas. Para Paiva et al. (2016), as metodologias ativas compartilham essa preocupação e por meio de diferentes estratégias visam operacionalizar práticas alternativas para o processo de ensino-aprendizagem. Entre as diferentes metodologias ativas, destaca-se a MP, que incita o educando a observar a realidade de modo crítico e possibilita estabelecer uma relação entre a realidade com a temática estudada. 
Conforme Morán (2015), este tipo de metodologia deve ser adotada se a pretensão é formar estudantes proativos, pois os envolve em atividades complexas, que precisam de decisões, de resultados e de conclusão crítica a respeito dos achados. A significação do ensino depende do sentido que se dá à aprendizagem e a significação da aprendizagem depende das atividades geradas pelo ensino (SAINT-ONGE, 2001). Desta forma, na MP adotada no curso, se privilegiou 0 ato de investigar, avaliar e decidir sobre distintas situações apresentadas no processo de experimentação, que resultasse na construção de novos saberes, caminhando do simples para o complexo.

Para Zompero e Laburu (2011), o ensino embasado na prática investigativa possibilita aprimorar as habilidades cognitivas, a cooperação entre os estudantes e a compreensão do trabalho científico. Este entendimento se ampara na mudança de concepção inicial dos educandos sobre o que é Ciência, que é restrita a cientistas malucos, explosões, etc., para uma visão que associa Ciência a métodos experimentais, observações, formulações de problemas e hipóteses. Nossos achados reiteram a inserção, na metodologia tradicional, de metodologia problematizadora aliada a temas urgentes, que permitem a ampliação da visão de Ciência dos educandos (NEVES et al., 2017).

Cruz et al. (2016) consideram que atividades de experimentação que utilizem a MP, com caráter lúdico e dedutivo, auxiliam o estudante a descobrir relações funcionais entre os conteúdos, testar teorias e contribui para a construção de concepções espontâneas acerca dos conceitos científicos. De fato, a observação e o estímulo à experimentação constituem um fator essencial no desenvolvimento do espírito científico. Essas condutas possibilitam ainda um olhar crítico e uma visão holística sobre a Ciência que, o ensino tradicional isolado, não é capaz de propiciar.

Ao utilizarem a Biofísica e Bioquímica para compreender como se intensifica o efeito estufa, os educandos ampliaram a visão da Ciência, relacionando a questão trabalhada com o Meio Ambiente. Para Brondani e Henzel (2010) esse tipo de atividade acresce novos valores e fortalece a consciência ambiental para que se possa de modo efetivo influir na mudança de atitudes e na percepção do que ocorre a nossa volta. Deste modo, se percebe a necessidade de um ensino voltado para os problemas atuais e urgentes, que prepare a população para viver e se desenvolver em um mundo interdependente e em harmonia com o ambiente.

$\mathrm{Na}$ perspectiva de Barros e Pinheiro (2013), diante da situação climática global, é basilar, não só a investigação sob o olhar das consequências deste para a vida humana, mas também no entendimento do que podemos fazer a respeito. Nesta conjuntura, é importante desenvolver práticas pedagógicas que versem sobre temáticas ambientais adotando metodologias que possam instigar o pensar do educando (BARROS; PINHEIRO, 2013). Assim, problematizar as ações do homem sobre o Meio 
Ambiente contribui para desenvolver a percepção dos estudantes para atitudes responsáveis sobre o meio como um todo.

$\mathrm{Na}$ perspectiva de associar Ciência e cotidiano dos educandos, Eno et al. (2016) ressaltam as plantas medicinais como instrumentos em atividades de Educação Ambiental e alimentar, que auxiliam no processo de ensinoaprendizagem e estreitam relações entre os agentes sociais envolvidos. A proposição deste tipo de atividade, por meio da experimentação com plantas medicinais no ambiente escolar, contribui para a desmistificação da Ciência, à medida que o estudante passa a se ver como cientista ao formular hipóteses e buscar soluções para os problemas enfrentados (SALGUEIRO et al., 2018). Deste modo, a abordagem sobre plantas medicinais na escola pode favorecer a relação teórico-prática de forma contextualizada e auxiliar na promoção da saúde e efetiva sensibilização das causas ambientais.

Para Carneiro et al. (2014), Ciência e Educação Ambiental são indissociáveis e podem ser trabalhadas por meio das plantas medicinais, pois estas são empregadas como recursos medicinais por grande parte da população. Segundo Fonseca (2012) é essencial atividades que abordem a temática plantas medicinais, ampliando a percepção dos educandos sobre este tema, pois estas somente apresentam valor medicinal quando usadas de maneira correta. Deste modo, a experimentação e problematização ampliaram as discussões dos educandos sobre a toxicidade das plantas e da maneira correta de consumo que não seja prejudicial à saúde.

Outra questão elencada, explorada e problematizada pelos educandos no curso de curta duração, foi a poluição ambiental. Para Fonseca e Bernardes (2014) é essencial discutir nos espaços educacionais a poluição atmosférica local, nacional e global. Estas discussões são importantes, considerando que a poluição do ar não respeita fronteiras, e devem servir para aproximar o educando destas questões para que ele saiba se posicionar criticamente.

Em pesquisa, Nicolussi et al. (2014) recomendam que o tema poluição atmosférica seja abordado nos espaços escolares, pois o comprometimento da qualidade do ar tem interferido na saúde da população, resultando em doenças respiratórias. As autoras citam que em regiões industriais, como em engenhos de processamento de grãos, a situação se agrava, gerando um grande dano a saúde da comunidade. Assim, é importante que o educando desenvolva uma visão abrangente sobre a problemática ambiental, pois esta atinge aspectos sociais, econômicos e políticos.

De fato, para Taha et al. (2016) trabalhar distintos temas por meio da experimentação motiva e instiga os estudantes a construírem perguntas relacionadas ao que acontece na natureza cotidianamente e, principalmente, a buscarem essas respostas. Na perspectiva de Kondrat e Maciel (2013) é imperativo estimular nos estudantes um espírito investigativo, de melhorias e descobertas, presentes num verdadeiro cientista, a partir de uma visão ambiental holística. 
A educação tradicional não prepara os indivíduos para a complexa realidade global, a Educação Ambiental torna-se uma necessidade, um processo contínuo e permanente que deve abranger todos os níveis escolares e etapas da educação formal e informal. (KONDRAT; MACIEL, 2013, p. 826).

Conforme Boff (2004), as questões ambientais, se revelam basilares para a população na medida em que reivindicam e preparam os sujeitos para desempenhar a cidadania por meio das relações sociais e com a natureza. Torales (2013) entende que apesar da expansão do tema, ele ainda é pouco abrangente e se caracteriza por ações pontuais e incipientes como práticas a serem potencializadas. Por isso, a relevância de propor abordagens que contemplem o tema Meio Ambiente em diferentes ações no espaço escolar.

Para Guimarães e Dorn (2015), a experimentação serve como comprovação do que foi discutido ou como mecanismo de testar hipóteses e induzir questões que inspirem a busca por respostas, retirando o educando da condição de ouvinte e inserindo-o ativamente no processo. Para Barros e Pinheiro (2013), esse tipo de discussão contribui para o entendimento a respeito de como as pessoas se relacionam com o meio ambiente, e se estarão dispostas a implementar ações necessárias para enfrentar esse tipo de problema. De fato, as discussões possibilitaram aos educandos pensar sobre questões que contribuam para a conscientização em relação aos danos causados ao meio ambiente.

\section{Conclusões}

Com base no exposto, conclui-se que o tema Meio Ambiente pode ser utilizado de forma transversal, associado com a MP, como ferramenta para o ensino de Ciências. Ademais, é notória a necessidade de implantação de diversas ações para efetiva consolidação de uma aprendizagem significativa na área da Ciência. Assim, é necessária a busca por estratégias de ensino que permitam uma práxis pedagógica capaz de superar os limites do tecnicismo tradicional trabalhado nas escolas e que vise a formação de sujeitos críticos, reflexivos e transformadores. Entende-se que a proposição de MP contribuiu de maneira significativa no processo de aprendizagem dos educandos, pois além de tornar o ensino investigativo, torna-o relevante e significativo.

Depreende-se que o curso, por meio de uma metodologia que considera o sujeito construtor de seu conhecimento, auxiliaram no processo de aprendizagem e na mudança de concepções sobre temas relacionados ao Meio Ambiente e a procedimentos científicos experimentais. As atividades propostas colaboraram principalmente para superar a maneira como a Ciência, pretensamente neutra, empirista, linear e elitista, é apresentada em contextos escolares. Conclui-se assim, que a proposta apresentada se configurou como uma atividade que, além de promover a Ciência, pode ser desenvolvida por 
professores de distintas áreas do saber, a partir de objetos de problematização pertinentes ao contexto escolar e aos educandos.

\section{Agradecimentos}

À Coordenação de Aperfeiçoamento de Pessoal de Nível Superior (CAPES) e à Fundação de Amparo à Pesquisa do Estado do Rio Grande do Sul (FAPERGS) pelo apoio financeiro à pesquisa. ACFS é bolsista CAPES/Brasil.

\section{Referências}

BARROS, H. C.; PINHEIRO, J. Q. Dimensões psicológicas do aquecimento global conforme a visão de adolescentes brasileiros. Estudos de Psicologia, v. 18, n. 02, 173-182, 2013.

BERBEL, N. A. N. A Metodologia da Problematização com o Arco de Maguerez: uma reflexão teórico-espistemológica. 202p. Londrina: Eduel, 2016.

BOFF, L. Saber cuidar: ética do humano - compaixão pela terra. $11^{\text {a }}$ ed. Petrópolis - RJ:Vozes, 2004.

BRASIL. Ministério de Educação e Cultura. Base Nacional Comum Curricular. 2017.2 Disponível em: $<$ http://basenacionalcomum.mec.gov.br/abase/>. Acesso em: jun. 2019.

BRASIL. Instituto Nacional de Estudos e Pesquisas Anísio Teixeira. Índice de Desenvolvimento da Educação Básica. Disponível em: <https://bit.ly/36jplM6 >. Acesso em: nov. 2019.

BRONDANI, C. J.; HENZEL, M. E. Análise sobre a conscientização ambiental em escolas da rede municipal de ensino. Revista Brasileira de Educação Ambiental, v. 05, 37-44, 2010.

CARNEIRO, F.; SILVA, M.; BORGES, L.; ALBERNAZ, L.; COSTA, J. Tendências dos estudos com plantas medicinais no Brasil. Revista Sapiência, v. 03, n. 02, 44-75, 2014.

CAUDURO, P. J.; LÜDKE, E. Revisão bibliográfica sobre o ensino de biofísica: uma análise de artigos de 2004 a 2016. Revista Vivências, vol. 13, n.24, 418424, 2017.

COLOMBO, S. R. A Educação Ambiental como instrumento na formação da cidadania. Revista Brasileira de Pesquisa em Educação em Ciências, v. 14, n. 2, 67-75, 2014.

CRUZ, A. C.; RIBEIRO, V. G. P.; LONGHINOTTI, E.; MAZZETTO, S. A Ciência Forense no Ensino de Química por Meio da Experimentação Investigativa e Lúdica. Química Nova Escola, vol. 38, n. 02, 167-172, 2016. 
ENO, G. É.; LUNA, R. R. LIMA, R. Horta na escola: incentivo ao cultivo e a interação com o meio ambiente. Revista Eletrônica em Gestão, Educação e Tecnologia Ambiental, v. 19, n. 1, 248-253, 2016.

FONSECA, M.C.M. Epamig pesquisa, produção de Plantas Medicinais para Aplicação no SUS. Espaço para o produtor, Viçosa: 2012.

FONSECA, R. G.; BERNARDES, M. B. Formação e ação: reflexões sobre a Educação Ambiental no curso de graduação em geografia da universidade de Coimbra -Portugal. Revista Brasileira de Educação Ambiental (Revbea), v. 10, n. 4, 36-51, 2015.

FREIRE, P. Pedagogia do oprimido. 42a . ed. Rio de Janeiro: Editora Paz e Terra, 2014.

GOMES, J. V. Modelo didático no processo ensino aprendizagem: mapeamento genético. Repositório-UFRRJ, Monografia, 2015. Disponível em: $<$ https://bit.ly/2kCf5Mz>. Acesso em: jun. 2019.

GUIMARÃES, C. C.; DORN, R. C. Efeito Estufa Usando Material Alternativo. Química Nova Escola, v. 37, n. 2, 153-157, 2015.

KONDRAT, H.; MACIEL, M. Educação Ambiental para a escola básica: contribuições para o desenvolvimento da cidadania e da sustentabilidade. Revista Brasileira de Educação, v. 18 n. 55, 825-846, 2013.

LANES, K. G.; LANES, D. V. C.; PESSANO, E. C.; FOLMER, V. O Ensino de Ciências e os Temas Transversais: Sugestões de Eixos Temáticos Para Práticas Pedagógicas no Contexto Escolar. Contexto e Educação, v. 29, n 92, 21-51, 2014.

LIMA, D. B.; GARCIA, R. N. Uma investigação sobre a importância das aulas práticas de Biologia no Ensino Médio. Cadernos do Aplicação, v. 24, n. 1, 201-224, 2011.

MAGALHÃES JUNIOR, C. O.; TOMANIK, E. A. Representações sociais de meio ambiente: subsídios para a formação continuada de professores. Ciência e Educação, v. 19, n. 1, 181-199, 2013.

MARQUES, M. P.; RIBEIRO, M.; GABRIEL, A.; CHAVES, S.; ZINELLI, M.; JESUS, M. Contribuições da Técnica de Ensino Brainstorming: Uma Experiência com Estudantes de uma Escola Estadual de Alta Floresta - MT. Revista Multidisciplinar e de Psicologia, v. 11, n. 37, 2017.

MUENCHEN, C.; DELIZOICOV, D. Os três momentos pedagógicos e o contexto de produção do livro "Física". Ciência e Educação, v. 20, n. 3, 617638, 2014.

MORÁN, J. Mudando a educação com metodologias ativas. In: Convergências Midiáticas, Educação e Cidadania: aproximações jovens. Vol. II. Org. SOUZA, C. A.; MORALES, O. T. PG: Foca Foto-PROEX/UEPG, 2015. 
NEVES, J. A.; CHARRET, I. C.; CARVALHO, S. A. Estudando a física do efeito estufa no 9o ano: uma abordagem visando a aprendizagem significativa. Experimentação no Ensino de Ciências, v. 12, n. 08, 66 - 87, 2017.

NICOLUSSI, F.; SANTOS, A.; ANDRÉ, S.; VEIGA, T.; TAKAYANAGUI, A. Poluição do ar e doenças respiratórias alérgicas em escolares. Saúde Pública, v. 48, n. 02, 326-330, 2014.

OLIVEIRA, E. B.; PAIXÃO, G. S.; SANTOS, F. N.; SAMPAIO, B. S. Temas geradores como contribuição metodológica para a prática docente. Revista Kiri-kerê, n. 02, 2017.

PAIVA, M.; PARENTE, J.; BRANDÃO, I.; QUEIROZ, A. Metodologias ativas de ensino-aprendizagem. SANARE, v. .15, n. 2, 145-153, 2016.

PEREIRA, K. B.; BRUM, V. S.; PIJUAN, P.L.; PESSANO, E. F. C.; FARIAS, F. M. O uso de plantas medicinais em uma unidade de estratégia de saúde da família na cidade de Uruguaiana. Educação Ambiental em Ação, n. 66, Ano 17, s.p., 2019.

ROCHA, L. D. L. S.; FARIA, J. C. N. M.; CRUZ, A. H. S.; REIS, A. A. S.; SANTOS, R. S. Drosophila: um importante modelo biológico para a pesquisa e o ensino de Genética. Scire Salutis, v.3, n.1, 37-48, 2013.

SALGUEIRO, A. C. F.; GOULART, A. S.; VIÇOSA, D. L.; VIÇOSA, C. C. L.; FOLMER, V. Resolução de problemas no ensino de Ciências: utilização de Artemia salina como modelo experimental para o estudo de plantas medicinais na escola básica. Revista de Ensino de Bioquímica, v. 16, n. 02, 31-47, 2018.

SAINT-ONGE, M. O ensino na escola: o que é e como se faz. 2. ed. São Paulo: Loyola; 2001.

SEGATTO, F. B. B. Conhecendo as formas de descartes do óleo saturado de cozinha para verificar a Educação Ambiental na escola. Revista Eletrônica em Gestão, Educação e Tecnologia Ambiental, v. 10, n. 10, 2122-2129, 2013.

SILVA, C. F. R. Modelos Didáticos utilizando Drosophila como ferramenta facilitadora no processo ensino-aprendizagem de Biologia. Atena, UFPE, Trabalho de Conclusão de Curso, 2018. Disponível em: $<$ https://bit.ly/2m2byaC>. Acesso em: jun. 2019.

TAHA, M. S.; LOPES, C. S. C.; SOARES, E. L.; FOLMER, V. Experimentação como ferramenta pedagógica para o ensino de Ciências. Experimentação no Ensino de Ciências, v. 11, n. 01, 138-154, 2016.

TORALES, M. A. A inserção da Educação Ambiental nos currículos escolares e o papel dos professores: da ação escolar à ação educativo-comunitária como compromisso político-pedagógico. Revista Eletrônica do Mestrado em Educação Ambiental, v. Especial, 01-17, 2013. 
VIÇOSA, L. C. S. C; TAHA, S. M; SOARES, L. E; FERREIRA, S. F. Unidade de aprendizagem: desenvolvendo a cidadania através da temática trânsito. Ciências e Ideias, v.7, n. 3, 88-100, 2016.

VIÇOSA, D. L.; FOLMER, V.; VIÇOSA, C. S. C. L.; SALGUEIRO, A. C. F. Drosophila melanogaster como modelo alternativo para cursos experimentais ofertados a estudantes de escolas públicas. In: Anais do IX SIEPE, v. 09, n. 04, 2017. Disponível em: <https://bit.ly/2kdbEMc>. Acesso em: jun. 2019.

WOLLMANN, E> M.; SOARES, F. A.; ROSSI, D.; LIMA, A. P. A formação de professores para a inserção da prática ambiental: um relato de experiência. Educação Temática Digital, v. 16, n. 3, 2014.

ZOMPERO, A. F.; LABURU, C. E. Atividades investigativas no ensino de ciências: aspectos históricos e diferentes abordagens. Ensaio: pesquisa em educação em ciências, v. 13, n. 3, 67-80, 2011. 